\title{
REPRESENTACIONES DE HOMOEROTISMO FEMENINO EN ALGUNOS TEXTOS LITERARIOS MEDIEVALES
}

EUKENE LACARRA LANZ1

Universidad del País Vasco/ Euskal Herriko Univertsitatea

\begin{abstract}
Resumen
El objetivo de este trabajo es examinar la representación genérica del homoerotismo femenino en algunos textos literarios. No es tarea fácil, porque en su mayor parte las relaciones sexuales entre mujeres han sido silenciadas tanto en la literatura de ficción como en los textos legales y eclesiásticos. En los textos analizados se observa una gran diferencia entre la representación de las mujeres que se han visto obligadas a travestirse de varones para mantener su virtud y las que desean yacer con otras mujeres. Las primeras se caracterizan como verdaderas viragos militares, que por su valor y sus virtudes se convierten milagrosamente en varones, restaurando así la ortodoxia del matrimonio. Las segundas, por el contrario, son objeto de burla y escarnio, especialmente si utilizan falos artificiales.

Palabras clave: -Homoerotismo, travestismo, sodomía, sexualidad, género, escarnio, medicina, fueros, Liber Gomorrhianus, cantigas, Speculum al foderi, Eiximenis, Chanson de Yde et Olive, Tristan de Nanteuil.
\end{abstract}

\begin{abstract}
The aim of this paper is to examine the gender representation of female homoeroticism in some literary texts. It is not an easy task because this type of sexual relations is practically silenced in literary fiction as well as in legal and ecclesiastical writings. In the texts I analyse one can see two different representations. Those women who are forced to take man's clothing to preserve their chastity, and those who desire to make love to women. The first ones are characterised as true military viragos, whose courage and virtues are rewarded and become miraculously men, thus restoring orthodox marriage. The second ones, however, are subject to mockery and derision, more so if they use artificial phalluses.
\end{abstract}

Key Words: Homoeroticism, travesty, mockery and derision, sodomy, sexuality, gender, medicine, law, Liber Gomorrhianus, poetry, Speculum al foderi, Eiximenis, Chanson de Yde et Olive, Tristan de Nanteuil.

La asimetría genérica consagrada a lo largo de siglos atribuyó a hombres y a mujeres una diferenciación genérica que presumiblemente se correspondía con sus respectivas naturalezas. Los discursos normativos subrayaban claramente las fronteras de género para evitar cualquier grado de confusión o trasvase. La caracterización genérica tenía implicaciones, jurídicas, físicas, emocionales, laborales, se extendía a la

1 Universidad del País Vasco. Correo-e: eukene.lacarra@ehu.es; Recibido: 25-03-2010; segunda versión: 30-04-2010. 
apariencia externa, repercutiendo en los códigos de vestido, en los ademanes, en las actitudes, en la gesticulación y en los más pequeños movimientos de la vida diaria de hombres y mujeres, en su identidad y en su manera de relacionarse en la sociedad. La sexualidad no se escapaba de esta caracterización, de modo que hombres y mujeres debían plegarse a su presunta naturaleza y cada género debía actuar de acuerdo al modelo considerado natural: activo-masculino y pasivo-femenino. Naturalmente, el matrimonio era el cauce legítimo y su objetivo primordial la procreación ${ }^{2}$. Las prácticas homoeróticas, el autoerotismo, el travestismo y la adopción del papel activo por parte de la mujer o del pasivo por parte del hombre se juzgaban como actos contra natura porque subvertían los paradigmas de género establecidos.

Durante la Edad Media las relaciones sexuales entre hombres concitaron el interés de juristas, teólogos, moralistas y médicos y hasta de los escritores de ficción, mientras que las relaciones entre mujeres con frecuencia se silenciaban o se dejaban en un segundo plano. Desafortunadamente, la investigación sobre la sexualidad ha seguido un camino similar, pues si los estudios sobre las prácticas sexuales entre hombres comenzaron en los años 80 con los estudios pioneros de Boswell (1980) y Greenberg (1988), las investigaciones sobre el homoerotismo femenino son todavía escasas, singularmente en lo que se refiere a los estudios relativos al periodo medieval (Murry, 1996: 191-233 y Bennet, 2000: 1-24). Laqueur (1992: 53) atribuye la mayor atención que recibían las prácticas masculinas a las consecuencias sociales y políticas que de ellas se podían derivar. Cualquier agravio contra un varón, bien fuera acusado de afeminado ("mollis") bien de ser el elemento pasivo ("pathicus"), podía llegar a amenazar el orden social. Para Jacquart y Thomasset la mayor vigilancia que se observa en las uniones sexuales entre varones provenía de la gravedad que se les atribuía por el peligro que presentaban para la conservación de la especie, pues desde la medicina se enseñaba que únicamente el semen masculino era generativo, por lo que su emisión no debía perderse al ser vertido fuera del vaso adecuado. La unión entre las mujeres, sin embargo, no presentaba esta amenaza a la conservación de la especie, al considerarse que el semen femenino no era generativo, por ello la condena era menor ${ }^{3}$.

Pedro Damián utilizó por primera vez el término "sodomía" en su Liber

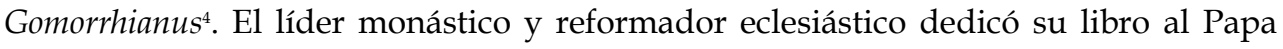
León IX (1048-1054), con el objetivo de erradicar la depravación de monjes y clérigos y establecer la castidad en los monasterios ${ }^{5}$. En su opinión, muchos incurrían en pecados que denomina de sodomía, y que agrupó en orden creciente de trasgresión en cuatro especies: auto-polución o masturbación, frotamiento o sujeción de las "virilia"

\footnotetext{
2 Surgen discrepancias cuando se plantea el placer sexual, que desde la medicina se defiende. Véase, Lacarra, (1993: 23). Para los discursos jurídicos, religiosos y médicos Lacarra, (2009: 205-228).

3 Jacquart y Tomasset (1989: 165). Esta menor condena se limitaba a la unión por frotamiento, pero no en caso de usar un falo artificial.

4 Sus fuentes son los penitenciales irlandeses, los del norte de Italia (ss. VI a X) y el Decretum de Burhard de Worms (965-1025). Para las fuentes eclesiásticas es fundamental consultar a Jordan, La invención de la sodomía en la teología cristiana (2002: 73-102).
}

5 Pedro Damian, Liber Gomorrhianus ad Leonem IX Romanus Ponteficem 2001, en especial caps. II y XXIII. 
(masturbación mutua), polución entre los muslos ("inter femora") y fornicación anal ("in terga"). Vemos, pues, que no limita la sodomía a las prácticas homoeróticas masculinas, sino que extiende el significado del término al onanismo y a aquellas otras prácticas en las que el semen se derrama fuera del vaso considerado apropiado. Las mujeres están ausentes de su discurso, salvo como víctimas de la lujuria masculina ${ }^{6}$.

En el discurso eclesiástico, no obstante, las prácticas homoeróticas femeninas no están del todo ausentes (Lacarra, 2009: 209-215). En los penitenciales anteriores al siglo XII se consideraron un pecado menos grave que las prácticas entre hombres y se asociaron a movimientos heréticos. En el sur de Francia se relacionaron especialmente con los cátaros, como menciona Guibert de Nogent en su autobiografía, y se observa en la bula del papa Gregorio IX contra ellos7. A partir de la reforma del Concilio IV de Letrán (1215) los pecados contra natura como la sodomía, la "fellatio", la bestialidad, las relaciones eróticas entre mujeres y la masturbación se condenaron como pecados muy graves. Tomás de Aquino sigue de cerca a los teólogos que le preceden, y considera que la Epístola a los Romanos de san Pablo (1-26), no se refiere únicamente a la cópula entre hombres sino también a la cópula entre mujeres. La Bula Periculoso de Bonifacio VIII, en 1298 es muestra de una severidad creciente dirigida contra los conventos femeninos, lugares en los que se quería poner fin a costumbres consideradas licenciosas, entre las que el homoerotismo sin duda tenía un lugar destacado (L'Hermite-Leclercq, 1997: 217 y Makowski, 1997).

No obstante, las relaciones sexuales entre mujeres fueron silenciadas en la mayor parte de los textos medievales cristianos, a diferencia de lo que ocurrió en las culturas greco-latina e islámica que al menos reconocen su existencia. Tanto en Grecia como en Roma existió una terminología concreta para denominarlas: "lesbias", "tribas", "hetairistria" en el caso de Grecia y "frictrix", "fricatrix", y "virago" en el de Roma (Brooten1996: 1-4). En los textos árabes medievales también se encuentra un término específico, "sahāqa", para designar las relaciones sexuales entre mujeres (Malta-Douglas, 2001: 123-141, y Amer, 2001: 179-198). Incluso algunos tratados árabes médicos contenían recetas no sólo para aumentar el deseo heterosexual sino también el deseo homoerótico femenino y prometían a las que tomaran esos afrodisíacos amores apasionados con otras mujeres. Sin embargo, los médicos medievales cristianos en general silenciaron este tema, aunque conocieron el Canon de Avicena (Lastique y Lemay, 1991: 78, n. 82).

Las legislaciones medievales tampoco se ocuparon de las relaciones sexuales entre mujeres, mientras que sí lo hicieron de la cópula entre varones. Aunque no observamos una terminología concreta, como indica Jordan, el vocabulario sexual es

6 Las mujeres aparecen citadas con frecuencia, pero no como pecadoras, sino como víctimas de la violencia sexual de los monjes. Se prevé la penitencia de los monjes que tienen relaciones heterosexuales, especialmente las que se consideran más graves, como el caso de "chi viola la donna che lui stesso sollevò dal fonte battesimale", porque la filiación espiritual se considera más grave que la carnal (Zavattero, Liber Gomorrhianus, cap. VII).

7 Benkov (2001: 108), donde también informa de que el dominico Guibert de Nogent insiste en ello en su autobiografía. 
rico en metáforas. ${ }^{8}$ Los términos se acuñan y luego se les agrega un significado sexual que varía en el tiempo y no es constante en todos los textos, de ahí la dificultad de su lectura (Jordan, 2002: 14-22).

A falta de una terminología precisa para la cópula entre varones, muchos fueros leoneses y castellanos mencionan entre los denuestos más graves expresiones como "fodido en culo" (Fuero de Ledesma ley 184), "fotudo īculo" (Fuero de Avilés ley 38)9, "ffudiduncul" (Fuero de Soria ley 481) o "fijo de fodido in culo" (Fuero de Alcaraz ley 80), todas ellas eran imprecaciones muy graves y quien las profiriera debía pagar multas cuantiosas. Estos denuestos tenían el significado de homosexual pasivo, aunque posiblemente también funcionaran como insultos graves de carácter general. Así parece ocurrir en algunas cantigas, con la variante "fududancua":

Baixo esa forma e sempre como adxectivo que modifica a velha en cinco das súas seis ocorrencias. Na sexta, combínase con puta. Xa non se asocia á homosexualidade, nen ó amor lesbio, senón que está utilizado cunha intención claramente vexatoria, que predomina sobre calquera significado concreto (Montero Cartelle, 2004: 211-212).

Algunos fueros como el Fuero de Alcaraz, el Fuero de Plasencia (08. 80) o el Fuero de Cuenca, se acercan en su terminología a los fueros reales al disponer la cópula entre varones bajo el título De los sodomíticos y precisar los castigos que conlleva:

Todo omne que fuere preso en pecado sodomítico, quemarle. Todo omne que a otro dixiere "yo te fodi por diuso" si probar se pudiere que uerdat es, quemarlos amos, si non quemar a aquel quel nimiga dixo ${ }^{10}$.

La legislación real también se ocupó de las relaciones masculinas condenándolas y castigándolas severamente (Lacarra, (2009: 216-219). Tanto en el Fori Iudicum como en su traducción al castellano, en el Fuero Juzgo, hay dos leyes que disponen sobre la cópula entre hombres (III.VI V y VI). En el proemio del título del Fori Iudicum se les denomina "masculorum concubitoribus" y en la traducción "sodomitas"11. Ambos consideran a esos hombres "excomulgados y malditos" y se les castiga a la castración si consintieron en el acto. La condena les obliga a ponerse bajo el poder del obispo en cuya tierra pecaron para que los encarcele o les imponga la penitencia debida. Sin embargo, sólo es castigado quien consintió, ya que cuando se trata de una violación, la víctima se considera inocente. En el caso de que los condenados sean hombres casados se dispone que sus hijos legítimos hereden todos sus bienes y que a sus mujeres se les

8 Baste ojear diccionarios eróticos como The Latin Sexual Vocabulary de Adams, el El latín erótico de Montero Cartelle, o el Dizionario storico del lessico erotico italiano de Boggione y Casalgno, para darse cuenta de la riqueza del léxico sexual.

9 Cela la registra como denuesto en el Fuero de Avilés en Enciclopedia erótica (II, s.v. culo). Hay un error de página en su cita, pues se encuentra en la 96 de la ed. del Fuero, no en la 94. Véase también Montero Cartelle (2004).

10 Montero Cartelle, cita en su art. “El latín, el gallego" (2004: 153-154) el Fuero de Alcaraz (81: 10-14, p. 242): Otrossi qual quier que a alguno dixiere: "Yo te fodi por el culo", si pudiere ser prouado que aquello uerdat es, amos sean quemados. Et si non, sea quemado aquel que tal maldat dixiere. El Fuero de Cuenca (353) tiene las mismas disposiciones para los sodomitas.

11 El Fori iudicum atribuye la primera de las dos leyes a Flavius Cintasvintus Rex y la segunda a Flabius Egica Rex, mientras que en el Fuero Juzgo se dice que la primera ley fue otorgada por Flavio Égica y la segunda por Flavio Recesvinto. 
devuelvan sus arras y sus bienes; además las mujeres se podrán volver a casar con quienes quieran.

El Fuero Viejo de Castilla (II.I.IX) incluye también el término "fudiduncul" entre los denuestos que causan injuria grave. La ley dispone que quien lo profiera deberá pagar al injuriado una multa de 500 sueldos si es hidalgo y 300 si es labrador. Contra las mujeres el denuesto mayor es puta sabida y quienes lo utilicen serán castigados con la misma multa que pagan los hombres cuando injurian a otros con la voz "fudiduncul"12.

La legislación alfonsí también era muy rigurosa con la cópula entre varones. En el Fuero Real (IV.IX) se les denomina sodomitas en el proemio del título. El legislador, como veíamos en el Fuero Juzgo también precisa el significado del término sodomita en su texto: "home <que> codicia á otro por pecar con él contra natura: "

Maguer que nos agravia de fablar en cosa que es muy sin guisa de cuidar, é muy sin guisa de facer; pero porque mal pecado alguna vez aviene que home codicia á otro por pecar con él contra natura, mandamos que cualesquier que sean, que tal pecado fagan, que luego que fuere sabido, que amos á dos sean castrados ante todo el pueblo, é después, á tercer dia, sean colgados por las piernas fasta que mueran, é nunca dende sean tollidos. (IV, 9, 2.)

La condena es mayor que en el Fuero Juzgo, pues además de ser castrados públicamente deben ser ajusticiados cabeza abajo, es decir en posición invertida humillante y expuestos a la vista pública de todos después de la muerte.

En las Siete Partidas también se legislan estas prácticas entre varones, bajo el título: "De los que fazen pecado de lujuria contra natura" (VII.XXI). Alfonso de nuevo considera oportuno explicar el término: "Sodomítico dizen al pecado en que caen los omes yaciendo vnos con otros contra natura, e costumbre natural". Al utilizar el género gramatical masculino no parece incluir a las mujeres. Sin embargo, Gregorio López a través de una glosa al título XXI de la Partida VII explicita su inclusión en la Pragmática de los Reyes Católicos otorgada el 22 de agosto de 1497 en Medina del Campo, a través de la glosa ${ }^{13}$.

Como vemos, la cópula entre mujeres se silencia en la legislación foral y en la real. El único código jurídico europeo conocido que castiga explícitamente la cópula entre mujeres es Li livres di jostice et de plet datado alrededor de 1270 y que proviene de la región de Orleans. Este código castiga a las mujeres como a los hombres y dispone para los reincidentes hasta en tres ocasiones castigos de creciente dureza. A los hombres se les castiga la primera vez a la castración de los testículos, la segunda a la castración del miembro viril y la tercera a morir en la hoguera. A las mujeres en las dos primeras ocasiones se les corta un miembro, no especificado y en la tercera se les castiga también

12 El denuesto puta sabida es muy grave, pues en el Fuero Juzgo (III.IV.XVII) se la define como la mujer libre que es "puta en la ciudad públicamientre", de la que se conoce que ha yacido muchas veces y con muchos hombres "sin vergüenza".

13 Se recoge en la Novisima recopilación, en Códigos antiguos de España II (1885). 
a la hoguera: "Feme qui le fet doit a chescune fois perdre membre et la tierce doit estre $\operatorname{arsse}^{\prime 14}$.

Entre los médicos no había consenso sobre las causas que llevaban al homoerotismo.. Algunos aducían que tales comportamientos no se debían a causas patológicas y que la responsabilidad debía recaer en la persona que las practicara (Jacquart y Thomasset, 1989: 162). Otros, sin embargo, los consideraban enfermos. Caelius Aurelianus en su De morbis chronicus, concluyó que la enfermedad se debía a causas fisiológicas, ya que los "mollis" sufrían de un exceso de deseo por exceso de semen (Laqueur, 1992: 44 y nota 58). Sorano de Éfeso atribuyó la inclinación homoerótica femenina a causas psicológicas y anatómicas. Consideraba que las mujeres que buscaban a otras mujeres padecían una enfermedad mental de la que se debían tratar. Aducía que durante esta enfermedad, las mujeres dejaban la pasividad propia de su naturaleza, se hacían activas y se servían de instrumentos hechos de cuero para poder penetrar agresivamente a otras mujeres. En su opinión eran tan lujuriosas y adictas al sexo que gozaban incluso en violar a otras mujeres (Martos Montiel, 1996: 154-155 y Brooten, 1996: 146-162). En su tratado de ginecología también argumentó la anatomía como origen de la enfermedad, al aducir el tamaño del clítoris como causa. Por ello recomendaba la clitoridectomía para las mujeres que tenían deseos amorosos hacia otras mujeres ${ }^{15}$. Su seguidor Pablo de Egina, incluyó en su tratado de cirugía un procedimiento de clitoridectomía ${ }^{16}$. Como es bien sabido esta cura tiene seguidores hasta la actualidad y en Europa se practicó hasta finales del siglo XIX.

Avicena en su Canon de medicina opina que las relaciones homoeróticas femeninas se producen cuando el hombre no puede satisfacer sexualmente a la mujer (Jacquart y Thomasset, 1989: 165), opinión que sigue el anónimo autor del Speculum al foderi ${ }^{17}$ :

E sapiats que a les fembres que los ve lo talent mol calt, que no se avenen ab elles los hòmens, $\mathrm{e}$ per aquesta rahó a y fembres d'aquestes que usen de gedoma si que és fet de cuyr lent e de cotó, confeccionat de dins a forma de vit, e usen ab ell e meten-lo en lo cony entró són fartas e perden lo desig (Solomon1986: 34).

En efecto, el uso del consolador que ya existía en Grecia y en Roma se conoció también durante la Edad Media. De hecho, se consideraba un adminículo esencial en las relaciones homoeróticas, pues no se concebían relaciones sexuales sin penetración. Su mención en los penitenciales es muy temprana, pues ya se encuentra en el penitencial

14 Crompton (1980-81: 13) comenta que no resulta claro el castigo que recibe la mujer y aventura que en las dos primeras ocasiones quizás incurra en la pérdida de un brazo o una pierna, mientras que en la tercera la pena sea la clitorectomía, pero creo que el término arsse es una variante de arse, adjetivo constatado a fines del siglo XIII en Enfances Ogier de Adenet Le Roi con el significado de quemado o como participio pasado de ardre, constatado en la Chanson de Roland (Trésor de la langue française http:/ / www.cnrtl.fr/definition/).

15 Brooten, cap. 5, donde señala las causas de la supuesta enfermedad y menciona que Pablo de Egina la considera un problema meramente físico y recomienda la clitoridectomía (p. 128). Véase también Brooten, (1996: 162-171).

16 Brooten, (1996: 165), opina que probablemente deriva de Celio Aureliano,.

17 Este anónimo sus fuentes y su fortuna editorial han sido analizadas por varios autores. Vallribera i Puig (1989: 249-58); Montero Cartelle (1991: 71-80); Alberni (2006: 257: 282). 
de Beda (ca. 672-735): "Si sanctaemoniales cum santaemoniales per machinam, annos" VII (Payer, 1984: 43, 68 y n. 136; del mismo 1991: 126-142). Hincmar de Reims (845882) y Burchard de Worms (965-1025) señalan que las mujeres se penetraban y se auto-estimulaban con instrumentos fálicos. Aunque desconocemos la frecuencia y extensión de tales prácticas, es evidente que el consolador, llamado "godemiché", "caralho", "baldrés" o "pissa" no fue desconocido desde la alta Edad Media y no era muy diferente del instrumento fálico forrado de cuero del que cuelgan unas correas que describe Luciano en el siglo II.

De la relación sexual entre mujeres nos enteramos también por Lo libre de les dones (Francesc Eiximenis 1981: 339):

e és quant mascle comet crim aytal ab mascle, o fembra ab hembra... Aquésts són per la ley de Déu sentenciats a cremar, hoc encara per les leys imperials. Car aquest peccat porta ab si corrupció de natura humana, e és tan leig que no.s deu nomanar. Car dien los sants que corromp l'ayre.

Eiximenis confirma el uso de los gedomichés en el siglo XIV en su obra Terç del crestià. Allí cuenta cómo se condenó a una mujer que se había disfrazado de hombre y que como tal se había casado dos veces con mujeres. La primera mujer al parecer virgen no se enteró de que su marido era también mujer o consintió en ello, porque nada se supo. La segunda mujer, sin embargo, que era viuda, se percató enseguida del uso de "godemiché" y acusó a su marido de ser mujer. El juez probó la veracidad de la acusación, pero al constatar que mientras vivió como hombre fue un hombre sabio que hizo mucho bien a la comunidad no le condenó a la hoguera, como prescribía la ley para ese delito y pecado sino que fue eximida de ese castigo y en su lugar fue condenada a la horca. No obstante, para que se supiera públicamente su crimen y pecado en la ejecución tuvo que llevar en el cuello el instrumento con el que sodomizaba a las mujeres ${ }^{18}$.

Evidentemente, las mujeres que vivieron en la Edad Media no se atuvieron siempre a los modelos sexuales a que la asimetría genérica consagrada les relegaba, si bien tenemos poca información de sus prácticas sexuales ${ }^{19}$. La supuesta impunidad de las mujeres que tenían relaciones sexuales con otras no se mantiene, como hemos podido observar en la legislación de Li livres di jostice et de plet, del caso relatado por Eiximenis y de otros casos (Segura Graíño, 2006: 139-147, Córdoba de la Llave, 2007:101 y Crompton, 1980-81: 17 y n. 33: 24). En todos ellos se castiga con la pena de muerte a mujeres acusadas de penetrar a otras mujeres con un falo artificial. La condena es menor cuando no usan consolador.

En el discurso literario las menciones de prácticas homoeróticas entre mujeres son muy escasas y domina la voz masculina. Hasta hoy apenas conocemos textos

18 Citado por J. Blackmore, “The Poets of Sodom” (1999: 217-218).

19 De esta falta dan cuenta quienes se acercan a estos estudios. Véanse Murray (1996: 191); Sautman, "Introduction: Charting the Field (2001, 1-2). Bennet (2000: 2-4), se queja de lo poco que sabemos sobre las prácticas sexuales de las mujeres ordinarias. En la Edad Media muy pocos documentos asocian explícitamente relaciones homoeróticas y de la escasa docena que se conocen todas se refieren al siglo XV y en todos los casos estas mujeres fueron encarceladas o ejecutadas por ello. 
escritos por mujeres que cuenten sus deseos sexuales, y mucho menos su amor por otras mujeres. Destacan como ejemplo casi único las epístolas de dos monjas procedentes del monasterio Tegernsee de Babiera escritas en el siglo XII. Es un intercambio emotivo donde las dos se duelen de la soledad que conlleva su separación (Dronke, 1968: 476-482). Hutcheson (2001: 261-266) ve una posible relación erótica entre Leonor de Córdoba y Catalina de Lancaster.

También hay algunos estudios sobre obras medievales que tocan marginalmente la sexualidad entre mujeres, inspirados probablemente en una de las metamorfosis de Ovidio, la famosa historia de Ifis y Iante. Recordemos que en esta historia Ifis nace niña, pero es criada en secreto por su madre como varón para evitar ser expuesta. A los diez años su padre le otorga como prometida a Iante, una niña bellísima también de 10 años. Ambas se enamoran, pero mientras que Iante está contenta porque desconoce la verdadera identidad de Ifis, ésta sufre al pensar que su amor es contra natura y que nunca podrá satisfacerlo. La angustia de la madre, Teletusa, y de su hija va in "crecendo" hasta que el día antes de la boda desesperadas imploran a la diosa Isis que las ayude. Ésta lleva a cabo la metamorfosis de Ifis en varón, quien se casa al día siguiente con su amada Iante (González Delgado, 999: 417-424).

Dos poemas épicos tardíos tienen una inspiración ovidiana notable. El primero, la Chanson de Yde et Olive, forma parte de una extensión de la epopeya de Huon de Bordeaux (ss. XIII-XV). Allí se narra cómo la princesa Yde huye del incesto del padre y abandona su reino vestida de hombre. Así travestida realiza tantas proezas militares que el rey de Roma, creyendo que es un valiente caballero, la casa con su hija. Yde intenta impedirlo sin éxito. Después de la boda Yde propone unos días de abstinencia a la bella Olive hasta que le descubre su verdadera identidad. Olive promete guardar el secreto, pero un joven escucha la confesión de Yde y lo comunica al rey, quien decide condenar a morir en la hoguera a ambas si es verdad. Sin embargo, una voz celestial salva a tiempo a Yde, quien se convierte en varón ${ }^{20}$. El segundo texto conocido procede también de una epopeya tardía, Tristan de Nanteuil. Su argumento es similar al ya comentado. Blanchandine, una sarracena, se viste de hombre para no ser reconocida por sus parientes. Una princesa sarracena se enamora apasionadamente de ella. Le obligan a casarse, pero por su falta de pene no puede valerse como hombre. Ante la amenaza de ser descubierta públicamente y condenada a la pena de muerte, reza a Dios. Cuando está a punto de ser descubierta la salva un gran ciervo que entra en palacio. Blanchandine se une a los cazadores y se pierde en una espesura. Allí oye una voz del cielo que le pregunta si quiere vivir como mujer o como hombre. Elige ser varón y cambia su nombre a Branchandin y nadie se entera de su primera identidad (Sautman, 2001: 199-232).

En estos textos los personajes se tratan con respeto y en ningún momento se recurre a la burla o al vituperio. Las metamorfosis de Yde y de Blanchandine, como la de Ifis, restauran la ortodoxia matrimonial a la vez que reafirman la maldad de las

20 Ed. Schweigel, 1889: 152-173. Véanse Perret, 1985: 328-340); Durling, 1990: 256-262) y Watt, 1998: 265-285). 
uniones entre mujeres que siguen siendo condenables a la muerte en la hoguera. En opinión de Perret la transformación se considera como recompensa a las damas de gran mérito (1985: 337).

Al lado de estas representaciones literarias que reconducen las transgresiones sexuales femeninas hacia el matrimonio heterosexual nos encontramos con otros textos de carácter cómico en los que la sexualidad de las mujeres es objeto de burla y vituperio. Este es el caso de un grupo de cantigas de escarnio y maldecir en el que a los personajes femeninos se les atribuye un ejercicio sexual exacerbado, indiscriminado o mercenario. También se les imputa de tratos sexuales con otras mujeres, aunque en menor número que a los hombres, e incluso de prácticas onanistas.

Dado el escaso número de textos literarios en los que se acusa a las mujeres de prácticas homoeróticas debemos considerar excepcional el pequeño corpus de cantigas de "escarnho y maldizer" de ese tema. Encontramos ocho poemas en los que se alude a relaciones homoeróticas (siete) y autoeróticas (una). El número es significativo, pues supone casi un $20 \%$ de las 43 cantigas protagonizadas por soldadeiras que computa Videira Lopes (1994: 213). Además, en dos de las cantigas encontramos la presencia de consoladores, que aunque frecuentes en la literatura antigua, griega y latina, son prácticamente invisibles en la ficción medieval. La voz poética femenina está ausente en estos textos mientras que la voz masculina ejerce un papel absolutamente dominante, describiendo el deseo de las mujeres en términos propios de la mofa y del vituperio, aunque exento de resabios morales.

La cantiga más conocida y citada de homoerotismo femenino es la de Afonso Eanes do Coton (Rodrígues Lapa $n^{\circ} 41$ ). La lectura de Rodrigues Lapa no deja lugar a dudas:

O sentido da cantiga é manifesto: trata-se de uma sáfica, Maria Mateus, que desejava as mulheres com a mesma violència dos homèns. São raros, na nossa poesia medieval, os documentos que aluden a esse vicio femenino (1995: 46).

Pimenta, por otra parte, sostiene que "O trovador desesperado duma sociedade que não pode satisfazer sexualmente $<\ldots$.. $>$ experimenta um medo inconsciente pavoródio aos portadores da inversão" y concluye que el poema es una amarga reflexión de Do Coton que descarga su angustia e indignación (1973: 123). Lanciani y Tabani concuerdan con la interpretación de Rodrigues Lapa, aunque añaden dos matices importantes, aducen que el autor "critica a lesbiana María Mateu, que gosta tanto dos homens como das mulheres" (Dicionário da Literatura 1993: 14). Blackmore, por contra, aduce que Do Coton:

He is not vilifying Mari Mateu but enganging in a ludic competition based in a solidarity of desire. Coton far from denouncing Mari Mateu as a pervert, openly addresses her in goodnature complicity

y concluye que "Maria Mateu y Fernán Díaz "anticipate what will come to be thought of in our century as lesbian and gay identity"(1999: 213).

Como vemos, todos interpretan que Mari Mateu es lesbiana, pero mientras Rodrigues Lapa subraya la violencia masculina de su deseo, Lanciani y Tabani señalan 
que a Mari Mateu también le gustan los hombres, lo que podría suponer que la mujer tiene prácticas homoeróticas, pero no necesariamente identidad lesbiana ${ }^{21}$. En esto contrasta con la posición de Blackmore que ve en el poema una anticipación a la identidad sexual que, en términos de Foucault, no es posible antes del siglo XIX.

Un análisis detenido del poema ofrece otras lecciones posibles. Es importante señalar que se trata de una cantiga de "mal dizer". Do Coton utiliza un léxico obsceno disfémico (cono) con el que degrada a todas las mujeres, que se ven reducidas por el recurso de la sinécdoque a su órgano sexual (Montero Cartelle, 2007: 391-400). Este uso descubierto de "palavras que queren dizer mal", así como el recurso a la "adscriptio" para vituperar a la receptora, Mari Mateu, confirman que se trata de una cantiga de "mal dizer". La ausencia de "aequivocatio" en el léxico no evita, sin embargo la duplicidad del texto. La voz masculina se dirige a Mari Mateu y le informa de que se tiene que marchar porque no puede conseguir mujer: “Marí' Mateu, ir-me quer'eu d'aquen/ porque non poss'un cono baratar" (vv.1-2). El uso de pronombres indefinidos "alguen" y "algũ[a]" esconden la identidad del hombre y de la mujer a las que hacen referencia. No le agrada el coito con un hombre que está dispuesto a ofrecerse "alguen que mi o daria nõno ten" (v. 3) y una mujer le rechaza: "e algũ[a] que o ten non mi o quer dar" (v. 4). ¿Es el rechazo de esa mujer lo que le decide a marcharse? ¿Será la propia Mari Mateu quien le rechaza? De ser así, los dos últimos versos explicarían el rechazo: “Mari' Mateu, Mari' Mateu,/tan desejosa ch'és de cono com'eu”. ¿Es la voz masculina fiable? ¿a Mari Mateu no le gustan los hombres o simplemente no le gusta el poeta?

En la segunda estrofa el poeta ofrece más datos de interés. No parece evidente el problema que le impide comprar una mujer ("un cono baratar"). Ciertamente no es la falta de mujeres. Los dos primeros versos muestran claramente que Dios ha creado muchas mujeres y también que a muchos hombres no les gustan las mujeres. De los doce versos que componen las dos estrofas, en seis se insiste que Mari Mateu es tan ardiente y gusta tanto de "cono com'eu". ¿Qué pasa con las demás mujeres?

La lectura literal de que a Mari Mateu le gustan las mujeres tanto como a él es una lectura posible, pero no la única. La pericia de Eanes do Coton y su ingenio se muestra en la riqueza de otras lecturas posibles. Su fracaso amoroso puede esconder entre líneas algo de mayor calado: sus ardientes deseos hacia las mujeres y su rechazo a los avances de otros hombres lo defienden ante cualquier larvada acusación o sombra de sodomía. ¿Por qué no consuma sus deseos con mujeres? Nada se dice en la cantiga que indique que muchas mujeres desean a otras mujeres. Por el contrario, se indica que hay hombres que desean a otros hombres y hombres que no desean a las mujeres. Frente a acusaciones y sospechas de la abundancia de hombres que tienen deseos contra natura el poeta se presenta como la excepción, como un modelo que guarda las reglas naturales.

Por otra parte, cabe la lectura de que su fracaso amoroso se deba a que Mari Mateu le ha rechazado y llevado del despecho se defienda con la injuria acusándole

21 Foucault (1984). Véase la crítica de Lochrie (1997: 9) a Foucault y su conclusión de que en la Edad Media no existían identidades homosexuales sino prácticas sexuales homoeróticas. 
de lesbianismo. El refrán: “Mari' Mateu, Mari' Mateu,/ tan desejosa ch'és de cono com'eu" podría ser tanto un sentimiento de la complicidad que comparte con la mujer como indica Blackmore, como una imprecación, un insulto jocoso contra ella a quien denuncia de deseo contra natura.

La ambivalencia de la cantiga es evidente porque en ésta como en todas las cantigas de escarnio y mal decir la "aequivocatio" es la esencia del género. Así pues, cabe también la lectura de que a Mari Mateu le gusten los hombres, como también opinan Lanciani y Tabani. En ambas lecturas la voz poética se manifiesta dominante, y desde su altura moral el poeta presenta una sociedad llena de hombres y mujeres que tienen relaciones homoeróticas en la que él se encuentra desplazado por su heterosexualidad. Puede tratarse de un ataque jocoso al personaje mencionado, Mari Mateu, sea literario o real, llevado a cabo por medio de la degradación de todas las mujeres, que por medio de la sinécdoque son identificadas por su órgano sexual (Montero 1995: 429-447) y también es un ataque contra los hombres que tienen prácticas contra natura. Las CEM no son inocentes y el envilecimiento cómico contribuye a la burla, no exenta de una cierta ansiedad social, como argumenta Liu, que en este caso me parece manifiesta (2004: 58).

Traj agora Marinha Sabugal (Rodrígues Lapa n ${ }^{\circ} 49$ ), también de Eanes do Coton, es una cantiga incompleta y difícil de analizar. Rodríguez Lapa opina que parece haber una insinuación sexual maliciosa y, en efecto, parece que el poeta nos presenta a Marinha que ha traído de su tierra a una mujer vieja que quiere bien, pero no le corresponde. Quiere ir con ella a guerrear a los moros, en un combate que parece más sexual que militar, pero la vieja no es ducha para la guerra (Liu, 1999: 57-58). De lo poco que podemos colegir, porque probablemente le falte una estrofa, Afonso Eanes nos presenta a una mujer Marihna que toma el papel masculino activo, pero no logra satisfacer sus deseos. Como indica Mérida, "la "velha" es, por supuesto, un tópico de esta tradición, pero también un insulto. Se ha establecido, por consiguiente, un doble ataque a la mujer: moral y personal" (Mérida Jiménez, 1997: 199-200).

El poema de Alfonso X, Achei Sancha Anes encavalgada (Paredes, 2001: 103) aparece como una breve narración en tres estrofas, cuyo aparente movimiento es una viñeta jocosa del poeta que describe el apareamiento sexual de Sancha Anes con otra mujer. La aequivocatio se advierte desde el inicio en el refrán, por la duplidad del significado de mostea. Sancha se presenta como una mujer fea - ca nunca vi dona peior talhada (v. 3)--, enorme e informe - e quige jurar que era mostea (v.4) - como un carro de paja ("mostea") 22 o como una mustela, es decir como un animal que por su cuerpo pequeño y alargado podía meterse en todos los agujeros y madrigueras y que tenía un indudable doble sentido sexual ${ }^{23}$. Rodrigues Lapa la describe como:

22 El Gran Diccionario Xerais da Lengua define "mostea" como "feixe de cereal" y como "móllo (denominación que se lle aplica á persoa moi desaliñada)". En el Diccionario da Lingua Portuguesa, "mosteia" se define como "carrada ou molho de palha (de orig. Obsc.)". También

23 Paredes (2001: 105) señala que la mostea es también la mustela o comadreja, animal capaz de concebir por la boca y parir por las orejas por lo que tenía un sentido también sexual contra natura. 
retrato cheio de pitoresco e malícia duma dona de avantajadas formas e já entrada em anos, cavalgando pelas ruas estreitas duma aldeia. O termo de comparação é uma carrada de palha (mostea), que exprime admiràvelmente bem o vagaroso do andamento, a grossura das formas e as farripas esbranquiçadas dos cabelos (1995: 38).

La gracia del poema es que únicamente en la tercera estrofa nos damos cuenta de ello y es entonces cuando obtenemos el sentido completo. Sancha, descrita físicamente tanto como una mujer grande, o al revés pequeña y buscona, como una comadreja, aparece cabalgando sobre alguien que al final resulta ser una mula, es decir, otra mujer. El sentido de unión contra natura, viene reforzado por la exclamación "Ai, velha fududancua", que podríamos traducir libremente como ¡Ay, vieja sodomita! No hay que tomar al pie de la letra este denuesto. Sancha Anes lejos de representarse como la parte pasiva es sin duda la parte activa que cabalga su mula y parece hacerlo como una mustela, introduciéndose en la madriguera.

Sabemos por las investigaciones de Gonçalves que el término mula se utilizaba con el sentido de barragana, es decir de concubina o amante (1991: 37-45). Esta investigadora trae a colación el Livro Velho de Linhagens de Don Pedro Barcelos, donde se dice que Sancha Ferrandes, casada con Paio Soares de Valladares "foi mula d'el rei de Portugal, isto é, foi barregā de Afonso II" (1991:39). A partir de aquí menciona varias cantigas en las que mula y mulo se utilizan en encuentros homosexuales, incluida ésta cantiga (1991: 42).

En el poema de Joan Garcia de Guilhade Dona Ouroana, pois já besta avedes (Rodrigues Lapa $\mathrm{n}^{\mathrm{O}}$ 213) el poeta aconseja a Ourana, mujer de aficiones homoeróticas que las deje de lado y cabalgue con varones. En la primera estrofa la presenta como una mujer muy delgada y débil que apenas puede cabalgar, y le aconseja que cuando quiera hacerlo le traigan una bestia que tenga "caralho", en este caso sinedoque de varón. En la segunda estrofa continua la "aequivocatio" con el sustantivo "besta", los verbos "andar" y "ensillar". Debe procurar que los hombres no huyan, pues tenerlos es lo que la define como soldadeira. En la tercera le aconseja que no se aparte mucho de la calle pues perdería el rocín, y no ganará nada. Así, mientras tenga bestia segura, allí donde vaya todos le honrarán y la distinguirán de cualquier otra puta sodomita. El poema termina con el consejo de que elija siempre un macho sobre una hembra (Martins, 1977).

Los poemas de Joán Vaásquiz (Rodríguez Lapa, nº 244 y n² 247) se dirigen contra María Leve. El primero ataca la desavenencia de María Leve con una joven con la que al parecer mantiene relaciones oscuras, según rezan los versos 7 y 8 , pues una mujer como ella no puede vivir si no tiene una joven. Como apunta Rodríguez Lapa. La joven quiere vivir en un barrio de mala fama, y la vieja María Leve no tiene otra alternativa que seguirle, bien a su pesar. El segundo es una burla de la iniquidad de la mujer que no se confiesa de sus pecados que son grandes, sino que se lamenta de ser vieja, como si esto fuera el pecado.

El poema de Fernand'Esquyo (Toriello, 1976) dirigido a una abadesa y el de Pero García Burgalés a María Negra, son especialmente interesantes porque son los únicos en los que las mujeres se valen de un falo artificial, que denominan "caralho", para penetrar 
a otras mujeres, es el caso del poema de Esquyo, o para el onanismo, en el poema de García Burgalés. Como veíamos más arriba se consideraba un instrumento diabólico que servía para el autoerotismo y para el homoerotismo femenino activo. Sobre ambos textos ya he escrito en otro lugar (Lacarra, 2001: 149-162). Es singularmente interesante el estado religioso de la dama a quien Esquyo dirige la cantiga. La relación de esta cantiga con los escarnios contra monjas libidinosas es evidente, pues las invectivas contra la lujuria de las monjas tenían una amplia tradición lírica. La dignidad de la persona interpelada es alta, pues la víctima de la sátira es persona de nivel social elevado, lo que en el esquema de Ciceri (1991: 223-224) implicaría la trasgresión máxima. Sin embargo, al no revelarse el nombre de la abadesa ni del monasterio que rige, no se produce el desenmascaramiento propio de la trasgresión media o máxima y la invectiva parece alejarse de la víctima concreta para convertirse en un juego literario e integrarse en el grupo de cantigas cuyo objetivo es parodiar la cantiga de amor y provocar a la risa y al humor, no exento de lubricidad, por la supuesta o real conducta lujuriosa de la vida conventual y de sus superioras las abadesas.

La invectiva contra María Negra es un ejemplo de la insaciabilidad femenina (Lacarra, 2002: 90-92). El poeta se burla de esta soldadeira representada como "velha sandia" que ha dilapidado toda su fortuna en comprar "caralhos" o "pissas" que enferman y mueren pronto porque los mete en la "pousada" o en la "casa molhada" y por el exceso de humedad adolecen de los males típicos de las caballerías. Así en la primera estrofa ya señala: "pissa tem já amormada" que de acuerdo a Rodrigues Lapa se refiere al "doente do mormo", es decir, el muermo, que es una enfermedad de las caballerías que provoca ulceración e inflamación de la mucosa nasal y de los ganglios linfáticos. En la segunda estrofa advierte que la "pissa" morirá de "polmoeira ou de torcilhon", o se quedará "aaguada". La "polmoeira" era una enfermedad del ganado vacuno de características parecidas al muerno de la caballerías, finalmente, el "torcilhon" era también un cólico de animales y la "aaguada" se refiere también a una enfermedad del caballo por exceso de comida, enfriamiento o trabajo.

La utilización de falos artificiales podía conllevar la muerte en la hoguera, como hemos mencionado arriba, especialmente si se utilizaban para penetrar a otra, lo que es evidente en el poema de Esquyo porque los "caralhos" tienen cordones para que la mujer que montaba a otra se los atara a la cintura. En el caso de la masturbación también era más grave el uso del consolador. Ambos se calificaban de pecados contra natura y eran infamantes. Sin embargo, en los penitenciales españoles de los siglos $X$ y XI estudiados por Bezler (1994: 189), la masturbación tiene penas más leves que el coito entre personas del mismo sexo.

Como vemos son pocos los textos en los que se manifiesta el homoerotismo femenino y en todos domina la voz masculina. No obstante, en los textos épicos las mujeres actúan como sujetos y hacen oír su voz. Gracias a su valor, honestidad y castidad Dios las premia y las eleva mediante una trasformación milagrosa a la categoría de varón. Sus hazañas militares las llevan a alcanzar los puestos más altos, incluyendo la realeza y son ellas/ellos quienes gobiernan el reino, restauran la ortodoxia matrimonial 
y restablecen las normas que condenan a la hoguera a quienes cometen crímenes contra natura.

En las cantigas las mujeres carecen de voz y se presentan a través de la aequivocatio y la burla como objetos dominados por la lujuria. Su sexualidad trasgresora es objeto del desprecio, de la mofa y de la irrisión. El abundante léxico "encubierto" reduce en cierta medida la agresión verbal, aunque no faltan los denuestos. La conjunción de la comicidad y el vituperio tan propio de la misoginia está siempre presente y aunque falta la moralización explícita, tácitamente se las condena por su ardiente insaciabilidad, que es la causa evidente de sus prácticas contra natura, como afirmaba Avicena.

\section{APÉNDICE}

\section{Textos}

1. Afonso Eanes do Coton (Rodrígues Lapa $n^{\circ} 41$ ).

Marí' Mateu, ir-me quer'eu d'aquen, porque non poss'un cono baratar; alguen que mi o daria nõno ten, e algũ[a] que o ten non mi o quer dar. Mari' Mateu, Mari' Mateu, tan desejosa ch'és de cono com'eu!

E foi Deus já de conos avondar aqui outros, que o non an mester, e ar feze-os muito desejar a min e ti, pero que ch'es molher. Mari' Mateu, Mari' Mateu, tan desejosa ch'és de cono com'eu!

\section{Afonso Eanes do Coton (Rodrígues Lapa $n^{\circ} 49$ )}

Traj agora Marinha Sabugal

ũa velha que adusse de sa terra, a que quer ben, e ela lhi quer mal;

e faz-lh'algo, pero que [muito] lh'erra;

mais ora quer ir moiros guerreiar

e quer consigo a velha levar,

mais a velha non é doita da guerra. 


\section{Alfonso X (ed. Juan Paredes)}

Achei Sancha Anes encavalgada, e dix' eu por ela cousa guisada, ca nunca vi dona peior talhada, e quige jurar que era mostea; vi-a cavalgar per ũa aldeia e quige jurar que era mostea.

Vi-a cavalgar con un seu scudeiro, e non ia milhor un cavaleiro.

Santiguei-m'e disse: -Gran foi o palheiro onde carregaron tan gran mostea; vi-a cavalgar per ũa aldeia e quige jurar que era mostea.

Vi-a cavalgar indo pela rua, mui ben vistida en cima da mua; e dix' eu: -Ai, velha fududancua, que me semelhades ora mostea!, Vi-a cavalgar per ũa aldeia e quige jurar que era mostea.

4. Joan Garcia De Guilhade (Rodríguez Lapa n ${ }^{\circ}$ 213)

Dona Ouroana, pois já besta avedes, outro conselh' ar avedes mester: vós sodes mui fraquelinha molher e já mais cavalgar non podedes; mais, cada que quiserdes cavalgar, mandade sempr[e] a best' achegar a un caralho, de que cavalguedes.

E, cada que vós andardes senlheira, se vo-l' a besta mal enselada andar, guardade-a de xi vos derramar, ca, pela besta, sodes soldadeira e, par Deus, grave vos foi d' aver; e punhade sempr' en[a] guarecer, ca en talho sodes de peideira.

E non mo[o]redes muito na rua, este conselho filhade de min, ca perderedes logu'i o rocin e non faredes i vossa prol neũa; e, mentr' ouverdes a besta, de pran, cada $\mathrm{u}$ fordes, todos vos faran onra doutra puta fududancua 
$E$, se ficardes en besta mũar, eu vos conselho sempr'a [vos] ficar ant'en mũacho novo ca en mũa.

5. Joán Vaásquiz (Rodríguez Lapa nº 244)

Direi-vos ora que oí dizer de Maria Leve, assi haja ben, pola manceba, que se desaven dela; e, pois lh'ali non quer viver, ena Moeda Velha vai morar Dona María Leve, a seu pesar.

Ca atal dona com'ela guarir non pod'ali, se manceba non á; e vedes que oí, amigos, já: que, pois que se lh'a manceba quer ir, ena Moeda Velha vai morar Dona María Leve, a seu pesar.

Ca diz que morava ali mal, alhor, poi-la manceba sigo non ouver, e contra San Martinho morar quer; pola manceba que xi lh'ora for, ena Moeda Velha vai morar Dona María Leve, a seu pesar. Ca non pod'a manceba escusar, se na Moeda Velha non morar.

6. Ioán Vaásquiz (Rodríguez Lapa no 247)

María Leve, u se maenfestava, direi-vos ora o que confessava:

Sõo velh', ai, capelán!

Non sei hoj'eu mais pecado, bugesa de min; mais vede-lo que mi mais pesa: "Sõo velh', ai, capelán!"

Sempr'eu pequei i, des que fui foduda; pero direi-vos per que [son] perduda: "Sõo velh', ai, capelán!" 


\section{Fernand'Esquio (ed. Toriello)}

A vós, dona abadessa, de min, don Fernand' Esquyo, estas doas vos envyo, porque ssei que ssodes essa dona que as merecedes: quatro caralhos franceses, e dous aa prioressa.

Poys sodes amiga minha, non quer'a custa catar, quer'e [u] vus ja esto dar, ca non tenho al tan aginha: quatro caralhos de mesa, que me deu hua burgesa, dous e dous ena baynha.

Muy ben vos ssemelharán, ca sequer levan cordões de ssenhos pares de colhões; agora vo-los darám: quatro caralhos asnaes, enmanguados en coraes, con que caledes orans.

\section{Pero García Burgalés (Rodríguez Lapa n 386)}

Maria Negra, desventuirada, e por que quer tantas pissas comprar, pois lhe na mão non queren durar e lh' assi morren aa malfa[da]da? E un caralho grande que comprou, oonte ao serão o esfolou, e outra pissa tem já amormada.

E já ela é probe tornada, comprando pissas, vedes que ventuira: pissa que compra pouco lhe dura, sol que a mete na sa pousada; ca lhi conven que ali moira enton de polmoeira ou de torcilhon, ou, per força, fica ende aaguada.

Muit' é per aventuira menguada de tantas pissas no ano perder, que compra caras, pois lhe van morrer; 
e est' é pola casa molhada

en que as mete, na estrabaria

pois lhe morren, a velha sandia

per pissas berra, en terra deitada.

\section{BIBLIOGRAFÍA}

Adams. J.N. (1982): The Latin Sexual Vocabulary, Londres, Johns Hopkins University Press.

Alberni, Anna (2006): “L'edició en lletra gòtica de l'Speculum al foder (1917). Història d'un misteriós exemplar d'infern", Llengua \& Literatura, 17: 257-282..

Alfonso X (1885): El Fuero Real de España, en Códigos antiguos de España I,. M. Martínez Alcubilla (ed.), J. López Camacho impresor, Madrid.

Alfonso X (1885): Las siete partidas, en Códigos antiguos de España I, M. Martínez Alcubilla (ed.), J. López Camacho impresor, Madrid.

Amer, Sahar (2001): “Lesbian Sex and the Military: From Medieval Arabic tradition to French Literature", en Francesca Canadé y Sheingorn, Pamela (Eds.), New York, Palgrave, 179-198.

Amer, Sahar (2008): Crossing Borders: Love Between Women in Medieval French and Arabic Literatures, Philadelphia, University of Pennsylvania, 2008.

Benkov, Edith (2001): “The Erased lesbian: Sodomy and the Legal Tradition in Medieval Europe" en Francesca Canadé y Sheingorn, Pamela (Eds.), New York, Palgrave, 101-122.

Bennett, Judith, M. (2000): “'Lesbian-Like' and the Social History of Lesbianism", Journal of the History of Sexuality, 9: 1-24.

Bezler, Francis, (1994): Les pénitentiels espagnols. Contribution à l'étude de la civilización de l'Espagne chrétienne du haut Moyen Âge, Münster, Aschendorff Verlag.

Blackmore, Josiah y J. Hutcheson, G. S., (Eds.) (1999): Queer Iberia. Sexualities, Cultures, and Crossings from the Middle Ages to the Renaissance, Durham \& London, Duke University Press.

Blackmore, Josiah (1999): “The Poets of Sodom”, en Blackmore, Josiah y J. Hutcheson, G. S., (Eds.), Durham \& London, Duke University Press, 195-221.

Boggione, Valter y Casalegno, Giovanni (1999): Dizionario storico del lessico erotico italiano, Milán, Tea.

Boswell, John (1980): Christianity, Social Tolerance, and Homosexuality. Gay People in Western Europe from the Beginning of the Christian Era to the Fourteenth Century, Chicago, Chicago University Press.

Brooten, Bernardette J. (1996): Love between Women. Early Christian Responses to Female Homoeroticism, Chicago, Chicago University Press. 
Burger, Glenn y Steven F. Kruger (2001): Queering in the Middle Ages, Minneapolis, University of Minnesota,

Campbell, Mary Ann (1992): “Redefining Holy Maidenhood: Virginity and Lesbianism in Medieval England"; Medieval Feminist Newsletter 13, 14-15.

Cela, Camilo J. (1976): Enciclopedia del erotismo. Vol. II, Madrid, Ediciones Sedmay.

Ciceri, Marcella (1991): “Livelli di trasgressione-(dal riso all'insulto) nei canzonieri spagnoli", en Marginalia hispánica, Roma, Bulzoni, 221-248.

Clark, Robert L. A. (2001): “Joustin without a Lance”, en Francesca Canadé y Sheingorn, Pamela (Eds.), New York, Palgrave, 143-177.

Córdoba de la Llave, Ricardo (2007): Homicidio en Andalucía a fines de la Edad Media, Universidad de Granada.

Crompton, Louis, (1980-81): “The Myth of Lesbian Impunity: Capital Laws from 12701291", Journal of Homosexuality, 6, 11-25.

Damian, Pedro (2001), Il Liber Gomorrhianus di Pier Damiani trad. de Irene Zavattero. http://islab.dico.unimi.it/phmae/IZ/liber.htm

Diccionario de Lingua Portuguesa (19957), eds. J. Almeida Costa y A. Sampaio Melo, Portugal: Porto Editora.

Dronke, Peter, (1968): Medieval Latin and the Rise of the European Love-Lyric, Clarendon, Oxford, 1968, vol. II.

Durling, Nancy Vine (1990): "Rewriting Gender: Yde et Olive and Ovidian Myth", Romance Languages Anual, 1: 256-262.

Eiximenis, Francesc (1981): Lo libre de les dones F. Naccarato (Ed.), Curial Edicions Catalanes, Barcelona.

Foucault, Michel (1984): Historia de la sexualidad. I. La voluntad de saber, Madrid, Siglo XXI.

Fuero de Avilés (1865): Aureliano Fernández-Guerra y Orbe (Ed.), Madrid, Imprenta Nacional.

Fuero de Cuenca (1935): Rafael de Ureña y Smenjaud (Ed.), Madrid, Academia de la Historia.

Fuero de Plasencia (1987): Eloísa Ramírez Vaquero (Ed.), Mérida, Editora Regional de Extremadura, Junta de Extremadura.

Fuero Juzgo en latín y en castellano cotejado con los más antiguos y preciosos códices (1815): Madrid, Real Academia Española, Ibarra, Impresor de Cámara de S. M.

Fuero Juzgo (1885):, en Códigos antiguos de España I, ed. Marcelo Martínez Alcubilla (Ed.), Madrid, J. López Camacho impresor, Madrid.

Fuero Viejo de Castilla (1885): en Códigos antiguos de España I, ed. Marcelo Martínez Alcubilla (Ed.),, Madrid, J. López Camacho impresor, Madrid.

Fueros castellanos de Soria y de Alcalá de Henares (1919): Galo Sánchez (Ed.), Madrid, Centro de Estudios Históricos. 
García Herrero, María del Carmen (2005): Del nacer y el vivir. Fragmentos de la vida en la baja Edad Media. Zaragoza: Letras, Institución Fernando El Católico, Diputación de Zaragoza.

Gonçalves, Elsa (1991):, “A mula de Joan Bolo”, en Poesía de rei: tres notas dionisinas, Lisboa, Cosmos, 36-62.

González Delgado, Ramiro (1999): “Homoerotismo en las Metamofosis de Ovidio", en Amor y erotismo en la literatura, Congreso Internacional, Salamanca, Caja Duero, 417-424.

Gran Diccionario Xerais da Lingua Gallega (2000): Xosé Cid Cabido (Ed.), Vigo: Edicións Xerais de Galicia.

Greenberg, David F. (1988): The Construction of Homosexuality, Chicago, Chicago University Press.

Hutcheson, Gregory S. (2001): "Leonor López de Córdoba and the Configuration of

Female-Female desire", en Francesca Canadé y Sheingorn, Pamela (Eds.), New York, Palgrave, 261-266.

Jacquart, Danielle y Claude ThOMAsset(1989): Sexualidad y saber médico en la Edad Media, Barcelona, Labor.

Jordan, Mark D. (2002): La invención de la sodomía en la teología cristiana, Barcelona, Alertes.

Lacarra, Eukene (1993): “Parámetros de la representación de la sexualidad femenina en la literatura medieval castellana", Foro Hispánico, 5, 23-43.

Lacarra, Eukene (2001): "El consolador y la sexualidad femenina en una cantiga de Fernand d'Esquyo", en Canzonieri iberici.I, ed. P. Botta, C. Parrilla e I. Pérez Pascual, A Coruña, Università di Padova, Universidade da Coruña, Toxo Toutos, 149-162.

Lacarra, Eukene (2002): "Sobre la sexualidad de las soldadeiras en las cantigas d'escarhno e de maldizer", en Amor, escarnio y linaje en la literatura gallegoportuguesa, Bilbao, Universidad del País Vasco, 2002, pp. 75-97.

LACARrA, Eukene (2009): "Homoerotismo femenino en los discursos normativos medievales", en "Siempre soy quien ser solia". Estudios de literatura medieval en homenaje a Carmen Parrilla, eds. Antonio Chas Aguión y Cleofé Tato García, A Coruña, Universidade da Coruña, 205-228.

Lanciani, Giulia y Tavani, Giuseppe, (Or. y coord) (1993): Dicionário da Literatura Medieval Galega e Portuguesa, (org. y coord.), Lisboa, Caminho.

Laqueur, Thomas (1992): Making Sex. Body and Gender from the Greeks to Freud, Cambridige, Mass, y Londres, Harvard University Press.

Lastique, Esther y Lemay, Rodnite Helen (1991): “A Medieval Physician's Guide to Virginity", en Salisbury, Joyce E. (Ed.), New York \& London, Garland, 56-79.

Les Fueros d'Alcaraz et d'Alarcón (1962): Jean Roudil (Ed.) 2 vols. Paris, Klincksieck. 
L'Hermite-Leclercq, Paulette (1997), L'Église et les femmes dans l'Occident chrétien des origines à la fin du Moyen Âge, Brepols.

Liu, Benjamin (1999), "'Afffined to Love the Moor'. Sexual Misalliance and Cultural Mixing in the "Cantigas d'escarnho e de mal dizer", en Blackmore, J., Hutcheson, G. S., eds., Queer Iberia. Sexualities, Cultures, and Crossings from the Middle Ages to the Renaissance, Durham \& London, Duke University Press, 48-72.

Liu, Benjamin (2004), Medieval Joke Poetry. The Catigas d'Escarnho e de Mal Dizer, Cambridge, Mass \& London, Havard Studies in Comparative Literature.

Lochrie, Karma, "Desiring Foucault", Journal of Medieval and Early Modern Studies, 27 (1997), 3-16.

Makowski, E. (1997), Canon Law and Cloistered Women. Periculoso and its Commentators, 1298-1545, Washington, Catholic University of America.

Malta-Douglas, Fedwa (2001), “Tribadism/Lesbianism and The Sexualized Body in Medieval Arabo-Islamic Narratives", en Same Sex Love and Desire among Women in the Middle Ages, New York, Palgrave, 123-141.

Martínez Alcubilla, Marcelo, (1885) ed., Novisima recopilación, en Códigos antiguos de España, II, Madrid.

Martins, Mario (1977); A sátira na literatura medieval portuguesa, Lisboa, Amadora, Biblioteca Breve, 8, Instituto de Cultura Portuguesa.

Mérida Jiménez, Rafael M. (1993): “D'ome atal coita nunca viu cristão: Amores nefandos en los trovadores gallego-portugueses", en $O$ cantar dos trobadores, Santiago de Compostela, Xunta de Galicia, 433-437.

Mérida Jiménez, Rafael M., (1997): “La representación de la sexualidad femenina en un poema arábigo-andaluz y en cuatro cantigas de escarnio gallego-portuguesas Revista de poética medieval, 1, 193-204.

Mérida Jiménez, Rafael M. (2002): Sexualidades transgresoras. Una antología de estudios queer, Barcelona, Icaria.

Montero Cartelle, Emilio (1995): “La interdicción sexual en el gallego medieval: la expresión de los órganos sexuales femeninos", Verba, 22, 429-447.

Montero Cartelle, Emilio (2004): "El latín, el gallego y el léxico sexual del castellano", en Iucundi acti labores: estudio en homenaje a Dulce Estefanía Alvarez , coord. por María Teresa Amado Rodríguez et alii, Santiago de Compostela, Universidad de Sntiago de Compostela, 149-157.

Montero Cartelle, Emilio (2005): “Unha verba, moitos problemas e algunhas solucións. A linguaxe erótica no galego medieval", en As tebras alumeadas: estudos filolóxicos ofrecidos en homenaxe a Ramón Lorenzo, Coord. Ana Isabel Boullón Agrelo, Santiago de Compostela, Universidade de Santiago de Compostela, 205-218.

Montero Cartelle, Emilio (2007): “Palabras malas \& villanas (Alfonso X: Partidas). La oralidad en las tradiciones discursivas jurídicas" en Discurso y oralidad: Homenaje 
al profesor José Jesús de Bustos Tovar, Luis María Cortés Rodríguez (Coord.), Anejo 3 Oralia, Madrid, Arco/Libros, vol. 1, 391-400.

Montero Cartelle, Emilio (2008): "A mi dizen quantos amigos ey": Homenaxe ao profesor Xosé Luís Couceiro / coord. Por Esther Corral Díaz, Lydia Fontoira Suris, Eduardo Moscoso Mato, Santiago de Compostela, Universidade de Santiago de Compostela, 537-546.

Montero Cartelle, Enrique (1991): El latín erótico. Aspectos léxicos y literarios, Sevilla, Universidad de Sevilla.

Montero Cartelle, Enrique (1991): “Sobre el origen árabe del Speculum al foderi catalán y su relación con el Liber minor De Coitu salernitano, Anuari de Filologia. Secció D, Studia Graeca et Latina, 2:71-80.

Martos Montiel, Juan Francisco (1996): Desde Lesbos con amor. Homosexualidad femenina en la Antigüedad, Ediciones Clásicas, Madrid.

Murray, Jacqueline (1996): “Twice Marginal and Twice Invisible: Lesbian in the Middle Ages", en Handbook of Medieval Sexuality, eds. Vern L. Bullogh y Brundage, James A, eds. New York, London, Garland.

Novisima recopilación, en Códigos antiguos de España II (1885): ed. Marcelo Martínez Alcubilla, Madrid, J. López Camacho impresor, Madrid.

Paredes, Juan (Ed.) (2001): El cancionero profano de Alfonso X el Sabio, Japadre Editore, L'Aquila.

Payer, Pierre J. (1991): “Sex and Confession in the Thirteenth Century”, en J. E. Salisbury (ed.), New York \& London, Garland.

Payer, Pierre J. (1984): Sex and the Penitentials. The Developemnt of a Sexual Code 550-1150, Toronto, Univ. of Toronto Press.

Perret, Michèle (1985): “Travesties et transsexuelles: Yde, Silence, Grisende, Blanchandine", Romance Notes 25:3, 328-340.

Pimenta, Berta Martihna et alii (Eds.) (1978): “Dois aspectos da sàtira nos cancioneiros galaico-portugueses, "Sodomiticos" y "cornudos", Revista da Faculdade de Letras de Lisboa, serie 4: 2 , 113-128.

Rabinowitz, Nancy Sorkin y Lisa Auanger (Eds.) (2002): Among Women. From the Homosocial to the Homoerotic in the Ancient World, Austin, University of Texas Press.

Rodrígues Lapa, M. (1995): Cantigas d'escarnho e de mal dizer dos cancioneiros medievais galego-protugueses, Santiago de Compostela: Galaxia.

Salisbury, Joyce E. (Ed.) (1991): Sex in the Middle Ages. A Book of Essays, New York \& London, Garland.

Sautman, Francesca Canadé (2001): “Introduction” en Sautman Francesca Canadé y Sheingorn, Pamela (Eds.), New York, Palgrave, 
Sautman, Francesca Canadé (2001): “What Can they Possibly do Together? Queer Epic Performances in Tristan de Nanteuil", en Sautman Francesca Canadé y Sheingorn, Pamela (Eds.), New York, Palgrave, 199-232.

Sautman Francesca Canadé y Sheingorn, Pamela (Eds.) (2001): Same Sex and Desire among Women in the Middle Ages, New York, Palgrave.

Schweigel, $\operatorname{Max}$ (Ed.) (1889): Esclarmonde, Clarisse et Florent, Yde et Olive, drei Forsetzungen Der Cahnson von Huon de Bordeaux, Marburg, Anejo de Romanischen Philologie LXXXIII.

Solomon, Michael, ed. (1986): Speculumal foderi, Madison: Hispanic Seminar of Medieval Studies.

Segura Graíño, Cristina (2006): “Catalina Belunce. Una mujer apela a la justicia de los Reyes Católicos", en Mujer, marginación y violencia. Entre la Edad media y los tiempos modernos, Coord. Ricardo Córdoba de la Llave, Córdoba: Universidad de Córdoba, 127-147.

Toriello, Fernanda, ed. (1976): Fernand'Esquyo. Le Poesie, Bari, Adriatica Editrice.

Vallribera I PUIG, Pere (1989: “Un manuscrit medieval català sobre sexologia: Speculum al Foderi", Gimbernat: Revista Catalana d'Història de la Medicina i de la Ciència, 12: 249-58.

Vasvari, Louise O. (1999): “The Semiotics of Phallic Agresión and Anal Penetration as Male Agonistic Ritual in the Libro de buen amor", en Blackmore, J., Hutcheson, G. S. (Eds.), Durham \& London, Duke University Press, 130-156.

Videira Lopes, Graça (1994): A sátira nos cancioneiros medievais galego-portugueses, Lisboa, Editorial Estampa.

Watt, Diane (1998): “Behaving like a Man? Incest, Lesbian Desire, and Gender Play in Yde et Olive and Its Adaptations", Comparative Literature, 50: 4, 265-285.

Zavattero, Irene (2001): Il Liber Gomorrhianus di Pier Damiani. Omosessualità e Chiesa nel Medioevo, http://islab.dico.unimi.it/phmae/IZ/liber.htm. (Consultado en marzo 2010) 